\title{
The role of intimate partner violence and other health-related social factors on postpartum common mental disorders: a survey-based structural equation modeling analysis
}

\author{
Michael Eduardo Reichenheim ${ }^{1 *}$, Claudia Leite Moraes ${ }^{1,2}$, Claudia Souza Lopes ${ }^{1}$ and Gustavo Lobato ${ }^{3}$
}

\begin{abstract}
Background: Although studies suggest the relevance of intimate partner violence (IPV) and other health-related social characteristics as risk factors for postpartum mental health, literature lacks evidence about how these are effectively connected. This study thus aims to explore how socio-economic position, maternal age, household and marital arrangements, general stressors, alcohol misuse and illicit drug abuse, and especially psychological and physical IPV relate in a framework leading to postpartum common mental disorder (CMD).

Methods: The study was carried out in five primary health care units of Rio de Janeiro, Brazil, and included 810 randomly selected mothers of children up to five postpartum months waiting for pediatric visits. The postulated pathways between exposures and outcome were based on literature evidence and were further examined using structural equation models.

Results: Direct pathways to postpartum CMD arose from a latent variable depicting socio-economic position, a general stressors score, and both IPV variables. Notably, the effect of psychological IPV on postpartum CMD ran partly through physical IPV. The effect of teenage pregnancy, conjugal instability and maternal burden apparently happens solely through substance use, be it alcohol misuse, illicit drug abuse or both in tandem. Moreover, the effect of the latter on CMD seems to be entirely mediated through both types of IPV.

Conclusion: Although the theoretical model underlying the analysis still requires in-depth detailing, results of this study may have shed some light on the role of both psychological and physical IPV as part of an intricate network of events leading to postpartum CMD. Health initiatives may want to make use of this knowledge when designing preventive and intervention approaches.
\end{abstract}

Keywords: Intimate partner violence, Social determinants of health, Postpartum common mental disorder, Mental health, Structural equation model

\section{Background}

Although largely neglected by global health policies, mental disorders are estimated to account for $14 \%$ of the global burden of disease [1]. Beyond severe cases of mental health problems, there is a whole range of mental disorders showing up in basic health services, be they

\footnotetext{
* Correspondence: michael@ims.uerj.br

'Department of Epidemiology, Institute of Social Medicine (IMS), Rio de Janeiro State University (UERJ), Rua São Francisco Xavier 524, $7^{\circ}$ andar, Rio de Janeiro, RJ 20550-013, Brazil

Full list of author information is available at the end of the article
}

in patients in search of health care for physical illnesses or complaints, or patients seeking contact with services for preventive or follow up care (e.g., pre or postnatal care). Expected as a set to tap an array of non-psychotic disorders, these recurrent complaints have been brandnamed common mental disorders (CMD) or psychological distress in the late 1980s and since used in many papers [2-4]. A specific collection of symptoms most often includes depression, anxiety and somatic complaints [2,5]. CMD's comprise $90 \%$ of all of the psychiatric morbidities

\section{() BioMed Central}

(c) 2014 Reichenheim et al.; licensee BioMed Central Ltd. This is an Open Access article distributed under the terms of the Creative Commons Attribution License (http://creativecommons.org/licenses/by/2.0), which permits unrestricted use, distribution, and reproduction in any medium, provided the original work is properly credited. 
and, according to $\mathrm{WHO}$, need to be regarded as a major public health concern [6].

Population-based studies have shown that CMD are more prevalent among the poor, unemployed, persons with low social support or who have experienced stressful life events, alcohol and drug consumers, and those with less years of schooling [7-9]. Gender differences are also consistent in the literature $[10,11]$, with anxiety and mood disorders being approximately twice as common in women as in men [4], regardless if occurring in higher or lower income countries [12]. However, such gender differential rates are strongly age-related; the greatest differences occur in adult life, with no reported differences in childhood and few in the elderly $[12,13]$. It has also been recognized that CMD have important consequences not only to women, but also to the development and wellbeing of their children [14-16].

A comprehensive approach is required for understanding the higher prevalence of CMD among women. Recently, the role of genetic, biological and psychosocial characteristics as important determinants of women's mental health have been reinforced $[6,13,14,17]$, and better explanations regarding these intricate relations have been pursued [18].

Consistent evidence across different cultures and countries suggests that social and economic characteristics play an important role in postpartum CMD $[19,20]$. Several studies also suggest that the effect of socio-economic position on women's mental health is shaped by the ensuing reproductive circumstances [8], stressful life experiences [21], substance consumption [8], and features related to the prevailing marital relationship [21].

The relationship between life events and women's mental health in the postpartum period is also well established $[19,20,22]$ and research shows that stressful experiences tend to precede substance consumption and intimate partner violence (IPV) in the context of women's mental disabilities $[21,23]$. Similarly, early (youth/adolescent) pregnancy, unstable relationships, and the burden resulting from several young offspring to care for seem to converge in increasing the risk of developing depressive and anxiety symptoms after birth $[14,19,20,24]$. There is also evidence that these events are important predictors of IPV during pregnancy and postpartum [25] and are commonly associate with misuse or abuse of psychoactive substances $[21,23]$. Along the pathways leading to mental disorders among women, some studies show that the effect of alcohol misuse or illicit drug abuse are at least partially mediated by IPV $[21,26]$. It should be noticed that the available evidence consistently portrays violence as an end-point consequence (outcome) in the process, suggesting IPV as a proximal path leading up to CMD.

There is also a substantial literature focusing chiefly on violence between couples as a risk factor to CMD among women [27-30], including mood disorders during pregnancy and the postpartum period [14,31-34]. Yet, there is not much evidence on the role played by escalating acts of psychological and physical partner abuse on CMD following childbirth. Some nuances of these intricate relationships remain unclear, as psychological and physical abuse have been generally treated separately in epidemiologic studies, therefore hindering a better understanding of how these two dimensions effectively associate amid a complex system holding other important events. This is hardly surprising since most of the studies on the subject have employed traditional analyses [22,35-42], which preclude explicitly addressing mediating processes.

Putting it all together, it is clear that research on the relationship between IPV and women's poor mental health following childbirth still falls short on providing a comprehensive account [27]. An issue still requiring light concerns the pathways by which socio-demographic characteristics, stressful events, substance consumption and IPV relate to each other, and in tandem, to the lack of psychological well-being in the postpartum period. It is true that some evidence is available, but the focus has mostly been on specific relationships, failing therefore to offer a more inclusive and organic perspective. In an attempt to redress this gap, the present study focuses on how IPV during pregnancy relates to CMD among women in the postpartum period, amid other biopsychosocial and health-related social covariates forming a complex interconnected framework. The analysis uses structural equation models, thus allowing the simultaneous evaluation of direct and indirect effects of antecedent and mediating variables.

\section{Methods}

\section{Participants}

The sample included randomly selected mothers of children under 5 months of age who were waiting to be consulted in five large public primary health care (PHC) facilities of Rio de Janeiro, Brazil. These PHC units comprised a convenience sample of health centers located throughout the city and serving mostly health care users of low to moderate income and education living in adjacent areas. This broad geographical distribution sought a representation of different sociocultural contexts represented in the study population. In addition, these health facilities provided assistance through spontaneous demand or scheduled consultations in general practice, pediatrics, gynecology and obstetrics. Minor surgical procedures, vaccinations and general actions for health promotion were also offered. Each unit performed, on average, 1,300 pediatric consultations per month at the time of data collection.

Data collection occurred from January to July 2007. On every day shift, a list of children was prepared prior to the consultations. Next, a draw was carried out in 
order to determine which mother would be interviewed first. Following each interview, the list was rerun, and another draw was taken. Face-to-face interviews of c. 45 minutes involving a multi-dimensional questionnaire of 368 questions were conducted by previously trained female health professionals under the supervision of two field coordinators. Given some shared research purposes [25,43-51], women were considered ineligible when experiencing less than one month of intimate relationship with a partner during pregnancy or the postpartum period, if there was an absolute contraindication for breastfeeding, and if they had given birth to twins. Out of 853 women invited to participate in the study, 18 (2.1\%) were ineligible and, from the remaining 835, 24 (2.9\%) refused to participate. Only one woman had missing data in one of the variables to be modeled. The effective study sample thus included 810 women who were interviewed in a reserved area without the presence of anyone but the interviewer, after signing an informed consent. Anonymity and confidentiality were completely assured. Women were informed about available health care units providing special services and hostels for cases of domestic violence in various parts of the city of Rio de Janeiro, regardless of whether they were identified as victims or not. The study was approved by the Research Ethics Committee of Rio de Janeiro Municipal Health Department in conformity with the principles embodied in the declaration of Helsinki.

\section{Variables and measurements}

Figure 1 presents the direct acyclic graph (DAG) portraying the initial 'propositional' model put to testing. Derived from the literature reviewed in the Introduction, this model specifies five domains comprising socio-economic position, stressors, substance intake, intimate partner violence, and common mental disorders. Structural paths move from left to right respecting the conjectured hierarchical sequence of events. Variable details are provided next, including definitions and respective measurement tools (where applicable). Table 1 provides a summary of the coding according to how the variables were used in the main analysis using SEM.

\section{Socio-economic position}

The family's socio-economic position was represented through a 'latent' variable (factor) 'manifested' by three empirical variables: (1) the Brazilian Criterion of Economic Classification (BCEC); (2) an omnibus score based on key household conditions (HOUSE); and (3) women's schooling achievements (EDUC). The BCEC is a composite index comprised of a selected basket of available household assets and the educational status of the main breadwinner [52]. As recommended, the index was categorized into five strata, ranging from the richest (stratus A) to the most disadvantaged economic group (stratus E). HOUSE is formed by four characteristics, viz., availability and quality of water supply services, type of sewerage and sanitation, type of domestic refuse and garbage disposal system, and a variable seizing household density (persons/ rooms). The total score ranges from 0 to 7 [53]. For descriptive purposes, the index was further discretized into three levels (7, 6 and $\leq 5)$. Modeled as an ordinal score (0 to 12$)$, women's schooling was similarly dichotomized for descriptive purposes at the cut-off point of 9 years of completed schooling, which stands for the Brazilian basic education level (equivalent to middle school in the US and O-level in the UK).

\section{Stressors}

Four variables were selected to represent major stressor situations: stressful live events taking place during the latest pregnancy (STRESS); women's age at the beginning of the latest pregnancy (AGE); marital status as a proxy to the degree of conjugal instability (INSTAB); and the number of children under five at home as a proxy to the level of women's work load and burden (UNDR5).

Five closed questions/indicators were used to tap distressing life events during pregnancy, viz., death of the partner or a close relative, job loss by the women, job loss by her partner, forced eviction from home, and perceived unusual financial problems. The cumulative total score (0 to 5$)$ was used in the main analysis (modeling), but a three-level variable is presented for the purpose of descriptively highlighting the percentage of women with and without any stressor experienced during pregnancy. Age and number of children under five were used in the main analyses as continuous and ordinal variables, respectively. For descriptive purposes, the former was categorized with the aim of underlining the frequency of pregnancy among teenagers and in more mature women. Conjugal instability was defined as any situation except when the woman reported the same spouse throughout the latest pregnancy and thereafter, conditional on the partner being the father of the current child.

\section{Substance use}

Women's alcohol misuse (ALC) during pregnancy was measured through the TWEAK (Tolerance; Worried; Eyeopener; Amnesia; K/Cut-down) [54,55], while the CAGE (Cut-down; Annoyed; Guilty; Eye-opener), based on women's report (by proxy), was used to measure their partners' alcohol intake [56-58]. The Non-Student Drugs Use Questionnaire (NSDUQ) was used to identify illicit drugs abuse (DRUGS) [59], and women's report (by proxy) employed to characterize partner's intake of illegal substances.

Seeking the highest possible sensitivity, and in an attempt to deal with possible misreporting due to the proxy approach, both variables ALC and DRUGS were 


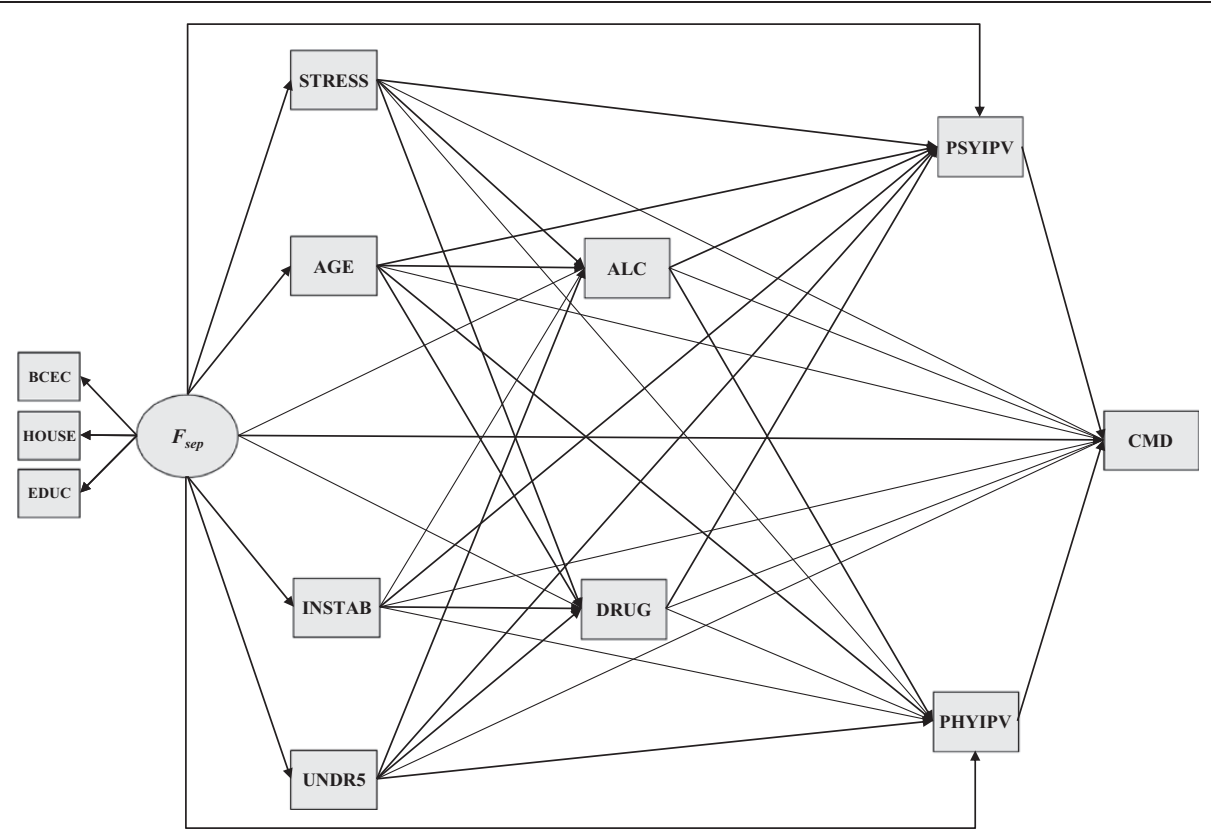

Figure 1 Direct acyclic graph depicting the propositional model. Variable definitions and mnemonics used in the DAG are provided in Table 1.

respectively modeled as ordinal scores comprised by the sum of the scores from both members of the couple. Thus, given that the total TWEAK and CAGE scores respectively varied from 0 to 7 and 0 to 4 , ALC could take values from 0 to 11 . Similarly, DRUGS would take values from 0 to 8 since the NSDUQ score ranges from 0 and 4. In presenting the profile of alcohol misuse, both TWEAK and CAGE scores were first dichotomized (yes/no) at the recommended cut-off points of 2 [54-58] and joined thereafter to form a four-level variable depicting whether alcohol misuse was either positive in one or both members of the couple. The same was done with NSDUQ, based on the recommended cut-off point of 1 [59].

\section{Intimate partner violence}

A Brazilian version of the Revised Conflict Tactics Scale (CTS2) was used to gauge IPV during pregnancy [60-62]. The CTS2 comprises 78 indicators describing acts perpetrated by the respondent and reciprocally by the partner. Although these items form five sub-scales, only two were of interest in this study: psychological aggression and physical violence during pregnancy. The sub-scale on psychological IPV (PSYIPV) comprises eight dichotomous items (whether the event ever happened or not and if so, if it occurred at least once during pregnancy) relating to women as perpetrators and/or victims. Raw scores could thus range from 0 to16. Likewise, physical IPV (PHYIPV) involves 12 items, with respective score thus varying from
0 to 24 . For descriptive purposes, both variables were classified in three levels ( 0,1 or $\geq 2$ events).

\section{Common mental disorders}

The Self-Reporting Questionnaire (SRQ-20) was used to assess CMD [63]. The SRQ-20 was developed by the World Health Organization (WHO) for a first approach to be used in primary health care services [64]. The scale consists of twenty dichotomous items covering depression (e.g., feel unhappy, find it difficult to enjoy daily activities, feel worthless, thought of ending your life been on your mind), anxiety (e.g., sleep badly, easily frightened, hands shake, feel nervous, tense or worried) and somatization symptoms (e.g., feel tired all the time, uncomfortable feelings in your stomach). Scores thus range from 0 and 20, which implicitly increase with the degree of psychological distress. This raw score was used in the modeling process, whereas a dichotomous variable applying the recommended cut-off point of $7 / 8$ for adult women was employed for descriptive purposes $[63,65,66]$.

Evidence of the SRQ-20 validity accumulate since its introduction in 1980 [3]. In Brazil, it was initially studied by Mari \& Williams $[65,66]$ who compared the instrument against the criterion of the Clinical Interview Schedule (CIS) [67], showing a sensitivity of $83 \%$, a specificity of $80 \%$, and an area under the ROC curve of 0.90 . More recently, the Brazilian version of the SRQ-20 was assessed in the elderly by Scazufca et al. [68], who showed a sensitivity of $76.1 \%$, a specificity of $74.6 \%$, and an area under ROC curve of 0.82 . The instrument's 
Table 1 Variables, instruments/composition and scaling/scoring (as used in the main structural equation models)

\begin{tabular}{|c|c|c|c|c|}
\hline Variable & (mnemonic) & Instrument/composition & Scaling & Scoring (categorization) \\
\hline \multirow{5}{*}{$\begin{array}{l}\text { Brazilian Criterion of Economic } \\
\text { Classification }\end{array}$} & \multirow[t]{5}{*}{ (BCEC) } & \multirow{3}{*}{$\begin{array}{l}\text { - Household assets: TV set, DVD set, radio, vacuum cleaner, } \\
\text { washing machine, refrigerator, freezer, bathroom, car }\end{array}$} & \multirow[t]{5}{*}{ Sum of item scores (0-34) } & - Stratum A (highest) $\rightarrow$ score $\geq 25$ \\
\hline & & & & - Stratum B $\rightarrow$ score $\geq 17-24$ \\
\hline & & & & - Stratum $C \rightarrow$ score $\geq 11-16$ \\
\hline & & - Presence of maid in the household & & - Stratum D $\rightarrow$ score $\geq 6-10$ \\
\hline & & - Educational status of the main breadwinner & & - Stratum E (lowest) $\rightarrow$ score $\leq 5$ \\
\hline \multirow[t]{4}{*}{ Household conditions } & \multirow[t]{4}{*}{ (HOUSE) } & - Household density: people per room & \multirow[t]{4}{*}{ Sum of item scores $(0-7)$} & - Maximum (best) $\rightarrow 7$ points \\
\hline & & - Type of house floor & & - Minimum (worst) $\rightarrow 0$ \\
\hline & & - Type of garbage/waste disposal system & & \\
\hline & & - Type of sewage & & \\
\hline \multirow[t]{2}{*}{ Women's schooling achievements } & \multirow[t]{2}{*}{$(E D \cup C)$} & \multirow[t]{2}{*}{ - Number of school years concluded } & \multirow[t]{2}{*}{ One year intervals } & - Maximum $\rightarrow 12$ years + \\
\hline & & & & - Minimum $\rightarrow 0$ \\
\hline \multirow{5}{*}{$\begin{array}{l}\text { Stressful live events taking place during } \\
\text { the latest pregnancy }\end{array}$} & \multirow[t]{5}{*}{ (STRESS) } & - Death of the partner or a close relative & \multirow[t]{5}{*}{ Sum of item scores (0-5) } & - Maximum $\rightarrow 5$ points (events) \\
\hline & & - Job loss by the women & & - Minimum $\rightarrow 0$ points (events) \\
\hline & & - Job loss by her partner & & \\
\hline & & - Forced eviction from home & & \\
\hline & & - Perceived unusual financial problems & & \\
\hline \multirow{2}{*}{$\begin{array}{l}\text { Women's age at the beginning of the } \\
\text { latest pregnancy }\end{array}$} & \multirow[t]{2}{*}{ (AGE) } & \multirow[t]{2}{*}{ - Number of years } & \multirow[t]{2}{*}{ One year intervals } & - Maximum $\rightarrow 44$ years \\
\hline & & & & - Minimum $\rightarrow 13$ years \\
\hline \multirow[t]{4}{*}{$\begin{array}{l}\text { Marital status (proxy to the degree of } \\
\text { conjugal instability) }\end{array}$} & \multirow[t]{4}{*}{ (INSTAB) } & $\begin{array}{l}\text { - Weather woman/mother currently had a partner or not during } \\
\text { pregnancy }\end{array}$ & \multirow[t]{4}{*}{ Composition } & \multirow{4}{*}{$\begin{array}{l}\text { - Stable } \rightarrow \text { woman reporting the same } \\
\text { spouse throughout the latest pregnancy } \\
\text { and thereafter, conditional on the partner } \\
\text { being the father of the current child }\end{array}$} \\
\hline & & $\begin{array}{l}\text { - Weather woman/mother currently had a partner or not during } \\
\text { the post natal period }\end{array}$ & & \\
\hline & & - Weather the referred to partner was the same in both periods & & \\
\hline & & - Weather partner was the father of the child & & \\
\hline \multirow{2}{*}{$\begin{array}{l}\text { Children under five at home (proxy to the } \\
\text { level of women's work load and burden) }\end{array}$} & \multirow[t]{2}{*}{ (UNDR5) } & \multirow[t]{2}{*}{ - Simple count } & \multirow[t]{2}{*}{ Sum of item scores $(0-3)$} & - Maximum (worst) $\rightarrow 3$ children \\
\hline & & & & - Minimum $\rightarrow 1$ child \\
\hline \multirow[t]{3}{*}{ Alcohol misuse during pregnancy (couple) } & \multirow[t]{3}{*}{$(\mathrm{ALC})$} & $\begin{array}{l}\text { - TWEAK (Tolerance; Worried; Eyeopener; Amnesia; } \\
\text { KCut-down) }[54,55] \rightarrow \text { women }\end{array}$ & \multirow[t]{3}{*}{$\begin{array}{l}\text { Sum of item scores }(0-7) \\
\text { [TWEAK] (0-4) [CAGE] }\end{array}$} & Joint score (women and partner) \\
\hline & & \multirow[t]{2}{*}{ - CAGE (Cut-down; Annoyed; Guilty; Eye-opener) [56-58] $\rightarrow$ partner } & & - Maximum (worst) $\rightarrow 10$ points \\
\hline & & & & - Minimum (best) $\rightarrow 0$ points \\
\hline \multirow{3}{*}{$\begin{array}{l}\text { Illicit drugs abuse during pregnancy } \\
\text { (couple) }\end{array}$} & (DRUGS) & - NSDUQ (the Non-Student Drugs Use Questionnaire (NSDUQ) & Sum of item scores (0-4) & Joint score (women and partner) \\
\hline & & on women and partners) & & - Maximum (worst) $\rightarrow 5$ points \\
\hline & & & & - Minimum (best) $\rightarrow 0$ points \\
\hline
\end{tabular}


Table 1 Variables, instruments/composition and scaling/scoring (as used in the main structural equation models) (Continued)

Psychological intimate partner violence $\quad$ (PSYIPV) • CTS2 (Revised Conflict Tactics Scale) [60-62] occurring during pregnancy (couple)

Physical intimate partner violence occurring (PHYIPV) during pregnancy (couple)

Common Mental Disorders (women)
Sum of item scores $(0-8)$

Joint score (women and partner)

- Maximum (worst) $\rightarrow 16$ points (+ve)

- Minimum (best) $\rightarrow 0$ points

Sum of item scores (0-12) Joint score (women and partner)

- Maximum (worst) $\rightarrow 24$ points (+ve)

- Minimum (best) $\rightarrow 0$ points

Sum of item scores (0-20) $\quad$ - Maximum (worst) $\rightarrow 20$ points (+ve)

- Minimum (best) $\rightarrow 0$ points 
factor structure has been studied by Iacoponi and Mari [69] and Santos et al. [70].

\section{Statistical analysis}

The structural equation modeling process employed Mplus' robust weighted least squares mean and variance adjusted estimator (WLSMV) [71]. Except for variables INSTAB (2 levels) and UNDR5 (3 levels), all others were assumed as normally distributed and thus modeled accordingly. Goodness of fit was evaluated using three indices [72,73]. The Root Mean Square Error of Approximation (RMSEA) incorporates a penalty function for poor model parsimony $[72,74,75]$. Values under 0.06 suggest close approximate (adequate) fit, whereas values above 0.10 indicate poor fit and that the model should be rejected $[71,76]$. The Comparative Fit Index (CFI) and the Tucker-Lewis index (TLI) represent incremental fit indices contrasting the hypothesized model to a more restricted nested baseline model, the "null model" [72,73]. Both range from zero to one and values $>0.9$ are indicative of adequate fit [77].

The model re-specification process took two sequential stages. Starting with the 'propositional' model shown in Figure 1, we first looked at indications of model misspecification observing suggested left out paths. To this end Modification Indices (MI) were used. A MI reflects how much the overall model chi-square decreases (improves) if a constrained parameter is freely estimated. Candidate paths involving conspicuous values $(\mathrm{MI}>10)$ were then examined for the actual amount of model fit improvement and for the magnitude of the ensuing freely estimated coefficients. The decision to explore and keep new paths also followed their theoretical meaningfulness [73].

The second stage involved systematically trimming out non-significant paths, i.e., coefficient estimates with $\mathrm{p}$-value $>0.05$. This process adhered to the hierarchical principal advocated in the model. The trimming process thus moved from left to right, starting with all paths stemming from $<F_{\text {ses }}>$, followed by $<$ STRESS/AGE/INSTAB/ UNDR5 $>$; then $<$ ALC/DRUGS $>$; and finally $<$ PSYIPV/ PHYIPV $>$. At each step, interim evaluations of MIs were carried out in search of any relevant path arising once the model had been simplified. The overall process stopped when none additional path was suggested by the MIs, while all remaining paths retained statistical significance given acceptable levels of model fit.

\section{Results}

\section{Profile of the study population}

The mean SRQ-20 score was 5.4 (s.d. 3.9) and $25.4 \%$ (95\% CI: $22.4 ; 28.4)$ women scored positive according to the cut-off point of $\geq 7$. Table 2 shows that according to the $\mathrm{BCEC}$, almost nine in ten women belonged to the lower-middle $(C)$ or lower socio-economic strata (D and E).
This is in agreement with only one-quarter of household conditions attaining the highest score (7) that summarizes all components - water, sanitation and refuse disposal, and household density - at their best, as well as with the overall level of achieved schooling. The population comprised $27.5 \%$ teenage pregnancies, $13.5 \%$ women reporting unstable conjugal relationships, and $25.8 \%$ involved in caring for two or more children. About half referred to at least one stressful life event occurring during pregnancy (52\%).

Alcohol misuse was found in almost half of couples (48\%), while $14.2 \%$ reported having used an illegal drug. Combining both, 51.6\% (95\% CI: 48.2 - 55.1) of couples referred to misusing any substance (not shown in Table 2). The frequency of at least one episode of IPV experienced either as perpetrator or victim by any member of the couple was high, be it of a psychological (82\%) or physical $(37.8 \%)$ type. While only $4 \%$ of the couples reporting an absence of psychological aggression referred to an episode of physical abuse, this figure rose to $45.2 \%$ among couples concomitantly reporting a positive psychological aggression.

Table 2 also shows the population profile according to CMD positive status. All variables are statistically significant. There is an increasing gradient of positive CMD as the situation indicated in each variable worsens.

\section{Main findings}

The first 'propositional' model fitted rather poorly RMSEA: 0.084 (95\% CI: 0.073 - 0.096); CFI: 0.907 and TLI: 0.763-, while the Modification Indices suggested two important paths to be included and freely estimated $(\mathrm{AGE} \rightarrow \mathrm{INSTAB}$ and PSYIPV $\rightarrow$ PHYIPV). With those, the second model fared better, but beyond mere adjustment issues, several paths lacked statistical significance at the 0.05 level and were candidates for further trimming. Following the analytical procedure outlined in the Methods section, it took another seven sequential steps to settle on a 'final' model.

Figure 2 shows the Direct Acyclic Graph of this ninth and 'final' model. Respective estimates and the adjustment indices are shown in Table 3. Intimate partner violence of both types is associated to CMD, conditional on other variables in the system. As mentioned before, there is now an explicit path between psychological aggression and physical abuse. Regarding PSYIPV, its direct 'effect' entailing other unspecified effectors/paths is only half that found for PHYIPV. However, the total effect of PSYIPV, based on the sum of the indirect effect (obtained from the products of the component coefficients $\beta_{\{\text {PSYIPV } \rightarrow \text { PHYIPV }}$ and $\left.\left.\beta_{\{\mathrm{PHYIPV}} \rightarrow \mathrm{CMD}\right\}\right)$ and the direct effect $\left(\beta_{\{\mathrm{PSYIPV}} \rightarrow\right.$ CMD $)$ is almost the same as that found for PHYIPV on CMD. Using a contrast involving extreme groups to illustrate, there is total effect of 2.12 (95\% CI: 1.45 - 2.79) points in the SRQ-20 scores when comparing women ten 
Table 2 Profile of the study population: univariate analysis and frequency of CMD (positive) according to variable status

\begin{tabular}{r} 
Varia \\
\hline Soci \\
A \\
$B$ \\
C \\
D \\
E
\end{tabular}

Univariate

Socio-economic strata (BCEC)

A

$B$

C

D

E

Household condition (score)

7 (best)

6

$\leq 5$ (worse)

Schooling (women)

$$
>9 \text { years }
$$$$
\leq 9 \text { years }
$$

Women's age at the beginning of latest pregnancy

$$
\begin{aligned}
& >35 \text { years } \\
& 20-35 \text { years } \\
& <20 \text { years }
\end{aligned}
$$

Conjugal instability

No

Yes

Number of children under 5 years

One
Two
Three

Stressful life events during pregnancy

$$
\text { None }
$$

One event

Two or more events

Misuse of alcohol

No
Woman only
Partner only
Both

Abuse of illicit drugs

No

Woman only

Partner only

Both

Psychological IPV during pregnancy

None

One event

Two or more events

15

81

369

330

15

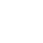

199

235

376

295

295
515

70

517

223

701

109

109

601

173

36

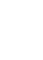

389

281

140

421

202

117

70

695

11

82

22

146

77

587

$$
\begin{gathered}
1.9(0.9-2.8) \\
10.0(7.9-12.1) \\
45.5(42.1-49.0) \\
40.7(37.3-44.1) \\
1.9(0.9-2.8)
\end{gathered}
$$

$24.6(21.6-27.5)$

$29.0(25.9-32.1)$

$46.4(43.0-49.9)$

36.4 (33.1 - 39.7)

$63.5(60.2-66.9)$

8.6 (6.7 - 10.6)

$63.8(60.5-67.1)$

27.5 (24.4 - 30.6)

$86.5(84.2-88.9)$

$13.5(11.1-15.8)$

$74.2(71.2-77.2)$

$21.4(18.5-24.2)$

$4.4(3.0-5.9)$

48.0 (44.6 - 51.4)

34.7 (31.4 - 38.0)

17.3 (14.7 - 19.9)

$52.0(48.5-55.4)$

24.9 (21.9 - 27.9)

14.4 (12.0 - 16.9)

$8.6(6.7-10.6)$

$85.8(83.4-88.2)$

$1.4(0.6-2.1)$

$10.1(8.0-12.2)$

$2.7(1.6-3.8)$

$18.0(15.4-20.7)$

$9.5(7.5-11.5)$

$72.5(69.3-75.4)$
CMD (+ve)

\begin{tabular}{lll}
\hline $\mathrm{n}$ & $\%$ & $\mathrm{p}$-value
\end{tabular}

2

$13.3(3.1-41.8)$

$14.8(8.5-24.3)$

$23.3(19.2-27.9)$

0.011

$30.3(25.5-35.4)$

$40.0(18.5-66.0)$

6

$16.5(12.0-22.4)$

$20.8(16.1-26.5)$

$<0.001$

49

$33.0(28.4-37.9)$

124

(28.4- 37.9$)$

$16.6(12.7-21.3)$

$83.3(78.6-87.2)$

$<0.001$

245

$12.3(06.5$ - 22.1)

$24.9(21.4-28.6)$

0.003

$32.2(25.8-39.3)$

59

$21.8(18.8-25.1)$

$40.5(33.1-48.4)$

$<0.001$

64

$22.5(19.3-26.0)$

$31.8(25.3-39.1)$

0.002

$44.4(29.1-60.9)$

$11.6(8.7-15.2)$

$33.1(27.8-38.8)$

$<0.001$

48.6 (40.4 - 56.9)

18.8 (15.3 - 22.8)

$29.2(23.3-35.9)$

36.8 (28.5 - 45.9)

$<0.001$

35.7 (25.3 - 47.6)

$22.2(19.2-25.4)$

$54.5(25.6-80.7)$

$40.2(30.2-51.2)$

$<0.001$

59.1 (37.7 - 77.5)

$13.0(8.4-19.5)$

23.4 (15.2 - 34.2)

$<0.001$ 
Table 2 Profile of the study population: univariate analysis and frequency of CMD (positive) according to variable status (Continued)

\begin{tabular}{lcccc}
\hline Physical IPV during pregnancy & & & & \\
None & 504 & $62.2(58.9-65.6)$ & 86 & $17.1(14.0-20.6)$ \\
One event & 87 & $10.7(8.6-12.9)$ & 27 & $31.0(22.2-41.6)$ \\
Two or more events & 219 & $27.0(24.0-30.2)$ & 93 & $42.5(36.1-49.1)$ \\
\hline
\end{tabular}

Note: Variable levels used for description are based on the scorings used in the main analysis (SEM). See Table 1.

points apart in PSYIPV, which is only slightly smaller than the direct effect of 2.27 (95\% CI: 1.34 - 3.20) regarding PHYIPV. Also, note that putative antecedent variables (STRESS, INSTAB, UNDR5, DRUGS and ALC) showed a direct link to PSYIPV, whereas only alcohol and drugs did so on PHYIPV.

The direct paths from alcohol misuse (ALC) and/or illicit drug abuse (DRUGS) to common mental disorders were dropped along the modeling process since they showed little significance once the other variables in the system were accounted for $\left(p_{\{\mathrm{ALC}} \rightarrow \mathrm{CMD}\right\}=0.399$ and $\left.\left.p_{\{\mathrm{DRUGS}} \rightarrow \mathrm{CMD}\right\}=0.511\right)$. Yet, even though there is no apparent direct relationship with CMD when antecedent events are controlled for, both are by themselves risk factors for any type of IPV. Thus, a connection still exists, the association of substance misuse or abuse on CMD now running through IPV.

Focusing on the more distal events, note that most 'propositional' paths stemming from the socio-economic factor $\left(F_{\text {sep }}\right)$ were retained in the 'final' model. Table 3 shows a direct effect on CMD of -0.98 (95\% CI: $-1.29--0.67$ ), but the total effect increases by $49 \%$ to -1.46 (95\% CI: $-1.79--1.14)$ when considering all pathways. Coeffi- cients are consistently negative showing that besides less CMD, there is also less substance misuse/abuse and fewer deleterious stressors (life events, teenage pregnancy, conjugal instability and maternal burden) as the socio-economic index - the latent score- raises. Conspicuously, though, the socio-economic determination on both types of IPV seems to be fully carried through mediating processes (stressors and substance misuse/abuse). In passing, note that the relative strengths of the indicators (manifests) used to summarize $F_{\text {sep }}$, albeit significant, are not the same. Noticing that estimates are standardized (to circumvent discrepant metrics and thus unstandardized coefficients that are difficult to compare), the indicator based on household conditions (HOUSE) seems to be the most discriminant.

Former (during pregnancy) and cumulative life events (STRESS) -death of kinship, job loss, eviction and financial worries - seem to contribute to increasing symptoms of CMD. As shown in Figure 2, all but one path remained in the 'final' model, conveying not only that there is an important total effect running directly to CMD (1.14; 95\% CI: 0.88 - 1.41), but that substance misuse and IPV also play their part on the total effect of 1.31

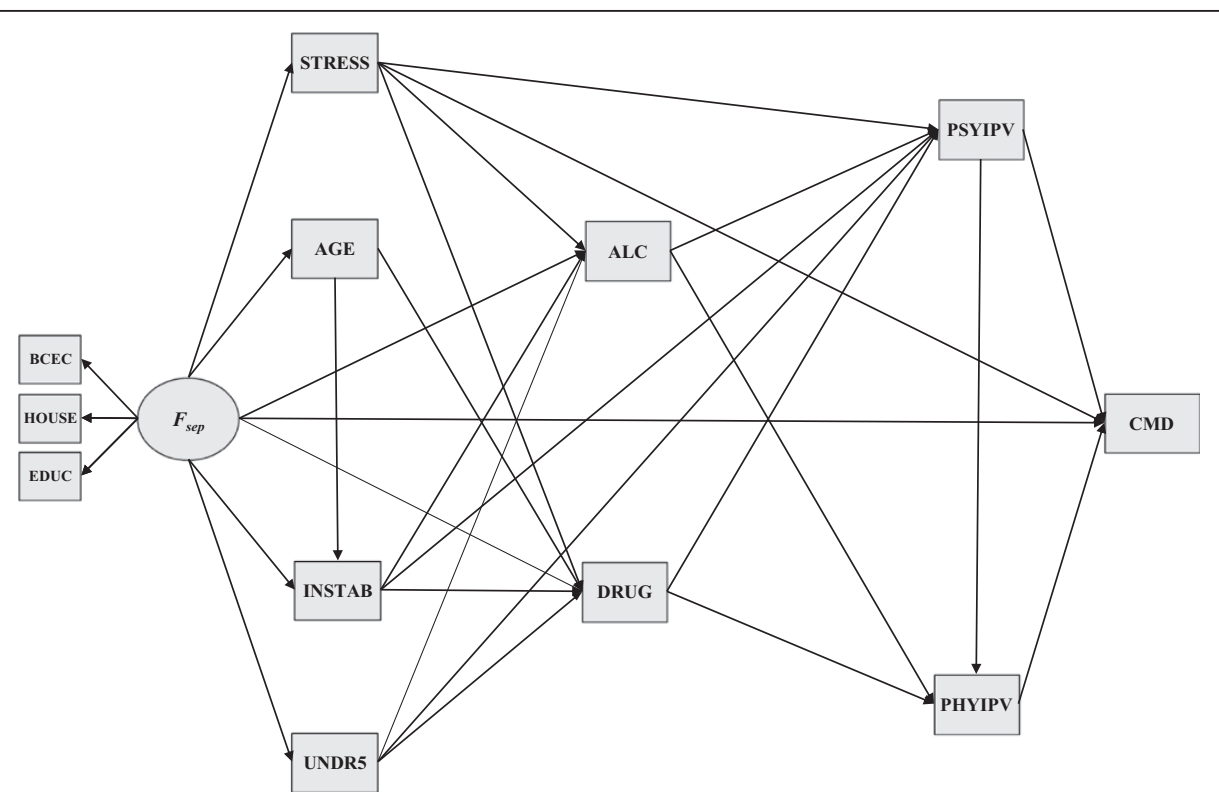

Figure 2 Direct Acyclic Graph depicting the final model. Variable definitions and mnemonics used in the DAG are provided in Table 1. 
Table 3 Path estimates and model fit indices of the final model shown in Figure $2(\mathrm{~N}=\mathbf{8 1 0})$

\begin{tabular}{|c|c|c|}
\hline Path & $\beta(95 \% \mathrm{Cl})$ & \\
\hline$\overline{\mathrm{PSYIPV}} \rightarrow \mathrm{CMD}$ & $0.112(0.030-0.194)$ & \\
\hline $\mathrm{PHYIPV} \rightarrow \mathrm{CMD}$ & $0.227(0.134-0.321)$ & \\
\hline STRESS $\rightarrow$ CMD & $1.145(0.877-1.413)$ & $* * *$ \\
\hline$F_{S E P} \rightarrow C M D$ & $-0.982(-1.294--0.669)$ & \\
\hline PSYIPV $\rightarrow$ PHYIPV & $0.440(0.386-0.494)$ & *** \\
\hline $\mathrm{ALC} \rightarrow \mathrm{PHYIPV}$ & $0.129(0.067-0.192)$ & * \\
\hline DRUGS $\rightarrow$ PHYIPV & $1.239(1.095-1.384)$ & $* *$ \\
\hline $\mathrm{ALC} \rightarrow \mathrm{PSYIPV}$ & $0.143(0.022-0.263)$ & *** \\
\hline DRUGS $\rightarrow$ PSYIPV & $0.667(0.271-1.062)$ & \\
\hline STRESS $\rightarrow$ PSYIPV & $0.557(0.297-0.817)$ & \\
\hline INSTAB $\rightarrow$ PSYIPV & $1.090(0.719-1.462)$ & * \\
\hline UNDR5 $\rightarrow$ PSYIPV & $0.429(0.127-0.730)$ & * \\
\hline STRESS $\rightarrow$ ALC & $0.379(0.222-0.536)$ & * \\
\hline INSTAB $\rightarrow$ ALC & $0.676(0.476-0.876)$ & * \\
\hline UNDR5 $\rightarrow$ ALC & $-0.355(-0.557--0.154)$ & * \\
\hline$F_{S E P} \rightarrow \mathrm{ALC}$ & $-0.496(-0.733--0.258)$ & * \\
\hline STRESS $\rightarrow$ DRUGS & $0.059(0.009-0.108)$ & * \\
\hline AGE $\rightarrow$ DRUGS & $-0.010(-0.018--0.003)$ & ** \\
\hline INSTAB $\rightarrow$ DRUGS & $0.183(0.127-0.240)$ & ${ }^{*}$ \\
\hline UNDR5 $\rightarrow$ DRUGS & $-0.094(-0.162--0.025)$ & ** \\
\hline$F_{S E P} \rightarrow$ DRUGS & $-0.160(-0.232--0.088)$ & \\
\hline$F_{S E P} \rightarrow$ STRESS & $-0.188(-0.263--0.114)$ & $* * *$ \\
\hline$F_{S E P} \rightarrow \mathrm{AGE}$ & $0.915(0.380-1.449)$ & ** \\
\hline $\mathrm{AGE} \rightarrow \mathrm{INSTAB}$ & $-0.041(-0.056--0.026)$ & \\
\hline$F_{S E P} \rightarrow$ INSTAB & $-0.312(-0.443--0.182)$ & \\
\hline$F_{\text {SEP }} \rightarrow$ UNDR5 & $-0.455(-0.591--0.319)$ & \\
\hline $\mathrm{BCEC} \rightarrow F_{S E P} \dagger$ & $0.512(0.434-0.591)$ & $* * *$ \\
\hline HOUSE $\rightarrow F_{S E P} \dagger$ & $0.694(0.624-0.764)$ & 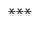 \\
\hline $\mathrm{EDUC} \rightarrow F_{S E P} \dagger$ & $0.582(0.506-0.657)$ & \\
\hline
\end{tabular}

\begin{tabular}{lcl}
\hline \multicolumn{2}{l}{ Model Adjustment } \\
\hline RMSEA & 0.042 & $(90 \%$ Cl: $0.031-0.053) ; p \leq .05=0.883$ \\
CFI & 0.967 & \\
TLI & 0.942
\end{tabular}

${ }^{*}$ p-value $<0.05 ;{ }^{* *}$-value $<0.01 ;{ }^{* * *} p$-value $<0.001$. tFully standardized estimates.

Note: see Table 1 for a full description of variables.

(95\% CI: 1.03 - 1.59). The presence of children to care for (UNDR5) runs independently from STRESS, yet shows a different pattern since its connection with CMD is fully mediated by other variables in the model.

Once the other events are taken into account, neither teen pregnancy seems to have some direct effect on CMD, nor is there any mediation by the two types of IPV and alcohol misuse. It looks as though the effect of teenage pregnancy/youth on the outcome (CMD) runs through the cumulative abuse of illegal drugs, irrespective of the presence of conjugal instability with which it is explicitly connected (AGE $\rightarrow$ INSTAB). Similarly to maternal burden (UNDR5), conjugal instability (INSTAB) failed to show a direct link to maternal CMD, but its effect runs through both types of IPV and substance consumption.

\section{Discussion}

This study reinforces previous findings on the high magnitudes of alcohol misuse, illicit drugs consumption, intimate partner violence and common mental disorders * among subjects attending public primary health care acilities in low and middle income countries [12,14], Brazil being among those $[78,79]$. Planning and implementing public health policies to address these issues are thus urgently required, including specific actions directed to the postnatal periods $[12,14]$.

A better understanding on how socio-economic determinants and CMD effectively interconnect may be auspicious in this respect. Although some studies had already shown an association of IPV and other psychosocial risk factors with depression and anxiety following childbirth $[19,20,22,41,80]$, to the best of the authors' knowledge, the present findings are the first to address this interconnectedness within a plausible and broad framework.

\section{Intimate partner violence and maternal mental health}

As mentioned before, comprehensive research jointly addressing IPV and women's mental health is still scarce [27] and the knowledge on the role that psychological and physical IPV play on CMD after childbirth has been far from consistent. While there are effectively some studies showing psychological [35,37,42], physical [38] or both types of IPV [41] as risk factors for maternal depression and anxiety, research suggesting a significant role of both forms of IPV are generally based on pooled variables or on disjoint models, which fail to properly evaluate their link.

According to the present findings, both manifestations of IPV have an important and quantitatively similar effect on the occurrence of depression or anxiety symptoms during the postpartum period. However, the respective patterns are quite different. Whereas physical IPV bears its full strength in directly influencing the postnatal mental health, psychological IPV seems to be partially running through physical IPV as a mediator. From a theoretical perspective, this seems plausible. For one, the literature has consistently pointed to a pattern of progressivity in the occurrence of IPV [81]. Commonly, IPV begins with sporadic acts of minor psychological aggressions that evolve to more severe forms of violence. In some cases, psychological violence triggers reactive and thoughtless physical acts that would otherwise not occur in its absence. A higher risk of CMD symptoms following 
this progression is also plausible. In effect, there is recent evidence that the probability of mothers developing depression and anxiety in the months following childbirth raises as the intensity of previous IPV and other social stressors also increase [22].

\section{Other psychosocial covariates}

The current findings may also help in understanding how socio-economic and some psychosocial conditions impact on maternal psychological status. Our results show that most relationships with CMD go through a cascade of mediating events. Recalling Figures 1 and 2, from many potential paths running directly to CMD, only four end up on this distal node. Besides both types of IPV mentioned before, direct links are exclusively observed from the socio-economic factor and stressful life events occurring during pregnancy. The effect of teenage pregnancy, conjugal instability and maternal burden apparently happens solely through substance use, be it alcohol misuse, illicit drug abuse, or both in tandem. Moreover, the effect of the latter on CMD seems to be entirely mediated through both types of IPV.

Studies based on traditional analyses have suggested a small effect of a person's socio-economic position on postpartum depression $[19,82,83]$. The same would have been inferred here too had only the direct path been taken into account (4th row in Table 3). However, the underestimation of the role played by the social and economic placement of a family is redressed when considering other indirect paths. According to our model that overtly avoids treating the other variables in the system exclusively as confounders but as mediators as well, the total effect rises sharply by almost $50 \%$. Results thus emphasize that socio-economic position poses an important strain on maternal mental health during the post-partum period and that there are several effectors involved in the process. Although maternal age, marital status and the number of children under five at home have been addressed in studies on pregnancy and postpartum depression $[19,82,83]$, results have suggested weak or even non-significant relationships with depression and anxiety after birth [19,20]. Once again, these results may be due to the lack of an explicit assessment of indirect mediating effects. While youth and teenage pregnancy, marital instability and maternal burden arising from high parity may not be strong enough risk factors per se to directly kindle postpartum CMD, they make up a fertile ground wherein deleterious habits and behaviors such as abuse of illicit drugs, excessive alcohol consumption or conjugal conflicts are facilitated. These, in turn, may well lead to depression and/or anxiety in a young mother expected to care fittingly for her newborn baby.

\section{Strengths and limitations}

The results of this study must be seen in the light of their strengths and weakness. Some methodological options stand on the positive side. The proposed theoretical model encompasses some of the most important psychosocial determinants of mental health in women $[12,14,19,20]$ and the quality of information was assured by employing well known and comprehensive measurement tools already adapted for use in Brazil.

The statistical approach may also have contributed positively given the benefits of structural equation models as outlined in the Introduction. Yet, although structural equation models, in principle, assume implicitly a temporal ordering of relationships, the cross-sectional approach used in the current study should not be overlooked. Admittedly, a longitudinal study would have allowed to directly handling and exploring the temporality of events. Nevertheless, some ethical issues would have emerged, which the crosssectional approach may have mitigated. In a prospective study, the identification of IPV would necessarily require action in an attempt to alleviate, reduce or even interrupt it, and thus inevitably influence the exposure-outcome relation.

The cross-sectional approach may have also influenced the recall of antecedent events, as for instance, 'moodsways' in CMD-positive women modifying the perception of social support. Although recognized as an important factor related to poor mental health $[14,84]$, we thus opted to avoid using social support in the analysis. As opposed to the other events that were measured through factual indicators, its awareness hinges on quite subjective current-state feelings and interpretations [85]. Ethical issues aside, a prospective design would therefore be optimal for suitably studying social support.

Another issue that could have potentially influenced the direction of the results concerns the use of a screening tool rather than a standardized clinical interview. Because the SRQ-20 is more sensitive to recent changes in psychological function and includes those with milder symptoms or transient psychological disturbance, one could expect some degree of false positives among the 'true cases' of CMD. Yet, this overestimation of true cases would only bring about bias to the effect measures of interest if it occurred differentially across IPV strata, which is not very likely.

As in any theoretically based modeling procedure, there is always scope for debate as to which phenomenon/ event should have been further incorporated to the analytical model and where it should have been placed. One such example concerns sexual IPV, which might have been considered, not only for its importance in the explanatory context of mental disorders as a whole, but because its omission may have introduced some residual confounding to the exposure-outcome relations of interest. 
Since sexual IPV is often positively associated to both psychological/physical IPV and CMD, the present estimates are thus likely inflated provided confounding effectively took place.

Debating the external validity of results is also relevant. In view of the subjects' characteristics, current findings seem applicable to populations commonly assisted in public primary health care units in Brazil and, possibly, other settings (countries) presenting similar socio-economic and cultural profiles. Still, some mothers under stronger stressors and severe depression, for instance, may have been missed in the study since they are more prone to social isolation and irregular visits to medical facilities. This type of selection bias may have attenuated the results since the inclusion of women scoring higher on the exposures and outcome would have given rise to stronger associations. On this account, the real situation may be even more pungent.

\section{Future directions}

The theoretical model underlying the analysis is still propositional and requires corroboration in forthcoming studies. Although based on solid literature, the outlined relationships must still be viewed as tentative and awaiting further testing. New studies would be justified to not only corroborate or refute the current model, but also to test whether the present findings are truly generalizable (as contended here) or if there are some modification effects by domain due to social, cultural or other factor specific to Brazil. Additionally, further research should also look into how knowledge on the psychosocial determinants of mood disorders following childbirth may be used to plan and implement effective measures targeting primary and secondary prevention of postpartum psychological disturbances [86-88]. This would come in hand with recent protocols suggesting systematic approaches for postpartum depression [89,90], including the identification and management of women/couples reporting IPV [91], alcohol misuse [92] and other deleterious social health issues [22].

\section{Conclusion}

The findings of this study reinforce the importance of IPV and other associated psychosocial characteristics as risk factors to common mental disorders following birth. In an attempt to mitigate or possibly prevent post-partum CMD, besides acknowledging socio-economic differentials, important leads may come from knowing that a woman is under stress arising from a dysfunctional relationships where IPV is extensive and constant; that she and/or her partner misuse alcohol or consume illegal drugs; and that there are several undesirable concurrent situations taking place such as teenage pregnancy, conjugal instability and/or house work overload due to many children needing to be taken care of. It is thus essential that health professionals become aware to the events accompanying CMD, particularly those of the psychosocial sphere. This could help them offer a more comprehensive assistance to mothers during the postpartum period, and by extension, allow them taking better care of their infants.

\section{Abbreviations}

CMD: Common mental disorders; IPV: Intimate partner violence; DAG: Direct acyclic graph; BCEC: Brazilian criterion of economic classification; HOUSE: Household conditions; EDUC: Women's schooling; STRESS: Stressful live events; AGE: Women's age (at the beginning of the latest) pregnancy; INSTAB: Conjugal instability; UNDR5: Number of children under five; ALC: Alcohol misuse; TWEAK: Tolerance; worried; eyeopener; amnesia; K/Cut-down; CAGE: Cut-down; annoyed; guilty; eye-opener; NSDUQ: Nonstudent drugs use questionnaire; DRUGS: Illicit drugs abuse; CTS2: Revised conflict tactics scale; PSYIPV: Psychological IPV; PHYIPV: Physical IPV; SRQ20: Self-reporting questionnaire; WLSMV: Weighted least squares mean and variance adjusted estimator; RMSEA: Root mean square error of approximation; CFI: Comparative fit index; TLI: Tucker-lewis index; MI: Modification indices.

\section{Competing interests}

The authors declare that they have no competing interests.

\section{Authors' contributions}

Author MER managed funds for the Project, designed the study, wrote the protocol, supervised the data collection process, undertook the statistical analysis and collaborated in writing (first author) the final draft of the manuscript. Author CLM managed funds for the Project, designed the study, wrote the protocol, supervised the data collection process and collaborated in writing the final draft of the manuscript. Author CSL collaborated in the literature review, and collaborated in writing the final draft of the manuscript. Author GL collaborated in designing the study and writing the protocol, coordinated the data collection process, and assisted in writing the final draft of the manuscript. All authors read and approved the final manuscript.

\section{Acknowledgments}

The research reported in this article was supported by the Carlos Chagas Filho Research Support Foundation of the State of Rio de Janeiro (FAPERJ), Grant E-26/110.365/2007-APQ1. The following authors were partially supported by the Brazilian National Research Council (CNPQ): MER, Grant 301221/2009-0; CLM, Grant 302851/2008-9; and CSL, Grant 302851/2008-9. All the authors are extremely grateful to the women that kindly accepted to participate in the study, and thankful to the health professionals of the PHC units where the research took place and to the fieldwork team.

\section{Author details}

${ }^{1}$ Department of Epidemiology, Institute of Social Medicine (IMS), Rio de Janeiro State University (UERJ), Rua São Francisco Xavier 524, $7^{\circ}$ andar, Rio de Janeiro, RJ 20550-013, Brazil. Family Health Master Program, Estácio de Sá University, Rua Riachuelo, 27, Rio de Janeiro, RJ 20230-010, Brazil. ${ }^{3}$ Fernandes Figueira Institute, Oswaldo Cruz Foundation (FIOCRUZ), Avenida Rui Barbosa, 716 - $3^{\circ}$ Andar, Rio de Janeiro, RJ 22250-020, Brazil.

Received: 28 July 2013 Accepted: 15 April 2014

Published: 5 May 2014

\section{References}

1. Murray CJ, Vos T, Lozano R, Naghavi M, Flaxman AD, Michaud C, Ezzati M, Shibuya K, Salomon JA, Abdalla S, Aboyans V, Abraham J, Ackerman I, Aggarwal R, Ahn SY, Ali MK, Alvarado M, Anderson HR, Anderson LM, Andrews KG, Atkinson C, Baddour LM, Bahalim AN, Barker-Collo S, Barrero LH, Bartels DH, Basanez MG, Baxter A, Bell ML, Benjamin EJ: Disability-adjusted life years (DALYs) for 291 diseases and injuries in 21 regions, 1990-2010: a systematic analysis for the Global Burden of Disease Study 2010. Lancet 2012, 380:2197-2223 
2. Mari JJ, Williams P: A comparison of the validity of two psychiatric screening questionnaires (GHQ-12 and SRQ-20) in Brazil, using Relative Operating Characteristic (ROC) analysis. Psychol Med 1985, 15:651-659.

3. Beusenberg M, Orley J: A user's guide to the Self reporting Questionnaire (SRQ). In WHO/MNH/PSF/94.8). Geneva: World Health Organization; 1994. http://whalibdoc.who.int/hq/1994/WHO_MNH_PSF_94.8.pdf.

4. Steel Z, Marnane C, Iranpour C, Chey T, Jackson JW, Patel V, Silove D: The global prevalence of common mental disorders: a systematic review and meta-analysis 1980-2013. Int J Epidemiol 2014, Epud ahead of print

5. Goldberg D, Huxley P: Common mental disorders: A biosocial model. London: Tavistock; 1992.

6. Draft comprehensive mental health action plan 2013-2020: Report by the Secretariat. http://apps.who.int/gb/ebwha/pdf_files/WHA66/ A66_10Rev1-en.pdf.

7. Anselmi L, Barros FC, Minten GC, Gigante DP, Horta BL, Victora CG: Prevalence and early determinants of common mental disorders in the 1982 birth cohort, Pelotas, Southern Brazil. Rev Saude Publica 2008, 42(Suppl 2):26-33.

8. Patel V, Kirkwood BR, Pednekar S, Weiss H, Mabey D: Risk factors for common mental disorders in women. Population-based longitudinal study. Br J Psychiatry 2006, 189:547-555.

9. Rognmo K, Torvik FA, Roysamb E, Tambs K: Alcohol use and spousal mental distress in a population sample: the nord-trondelag health study. BMC Public Health 2013, 13:319.

10. Eaton NR, Keyes KM, Krueger RF, Balsis S, Skodol AE, Markon KE, Grant BF, Hasin DS: An invariant dimensional liability model of gender differences in mental disorder prevalence: evidence from a national sample. $J$ Abn Psychol 2012, 121:282-288.

11. Kessler RC, Ormel J, Petukhova M, McLaughlin KA, Green JG, Russo LJ, Stein DJ, Zaslavsky AM, Aguilar-Gaxiola S, Alonso J, Andrade L, Benjet C, de Girolamo G, de Graaf R, Demyttenaere K, Fayyad J, Haro JM, Hu C, Karam A, Lee S, Lepine JP, Matchsinger H, Mihaescu-Pintia C, Posada-Villa J, Sagar R, Ustun TB: Development of lifetime comorbidity in the World Health Organization world mental health surveys. Arch Gen Psychiatry 2011, 68:90-100.

12. World Health Organization: Mental Health: New Understanding, New Hope. Geneva: WHO Press; 2001:178.

13. World Health Organization: Mental Health Atlas 2011. Geneva: WHO Press; 2011:82.

14. World Health Organization: Mental health aspects of women's reproductive health. A global review of the literature. Geneva: WHO Press; 2009.

15. Ferri CP, Mitsuhiro SS, Barros MC, Chalem E, Guinsburg R, Patel V, Prince M, Laranjeira R: The impact of maternal experience of violence and common mental disorders on neonatal outcomes: a survey of adolescent mothers in Sao Paulo, Brazil. BMC Public Health 2007, 7:209.

16. Servili C, Medhin G, Hanlon C, Tomlinson M, Worku B, Baheretibeb Y, Dewey $M$, Alem A, Prince M: Maternal common mental disorders and infant development in Ethiopia: the P-MaMiE Birth Cohort. BMC Public Health 2010, 10:693.

17. Accortt EE, Freeman MP, Allen JJ: Women and major depressive disorder: clinical perspectives on causal pathways. J Women's Health 2008, 17:1583-1590

18. Kendler KS, Prescott CA: Genes, environment, and psychopathology: understanding the causes of psychiatric and substance use disorders. New York: The Guilford Press; 2006.

19. Robertson E, Grace $S$, Wallington T, Stewart DE: Antenatal risk factors for postpartum depression: a synthesis of recent literature. Gen Hosp Psychiatry 2004, 26:289-295.

20. Wenzel A, Haugen EN, Jackson LC, Brendle JR: Anxiety symptoms and disorders at eight weeks postpartum. J Affect Dis 2005, 19:295-311.

21. Kendler KS, Gardner CO, Prescott CA: Toward a comprehensive developmental model for major depression in women. Am J Psych 2002 159:1133-1145.

22. Yelland J, Sutherland G, Brown SJ: Postpartum anxiety, depression and social health: findings from a population-based survey of Australian women. BMC Public Health 2010, 10:771

23. Kendler KS, Gardner CO: A longitudinal etiologic model for symptoms of anxiety and depression in women. Psychol Med 2011, 41:2035-2045.

24. Birmingham MC, Chou KJ, Crain EF: Screening for postpartum depression in a pediatric emergency department. Pediatr Emerg Care 2011, 27:795-800.

25. Moraes CL, Silva TST, Reichenheim ME, Azevedo GL, Oliveira ASD, Braga JU: Physical violence between intimate partners during pregnancy and postpartum: a prediction model for use in primary health care facilities. Paediatr Perinat Epidemiol 2011, 25:478-486.
26. Nayak MB, Patel V, Bond JC, Greenfield TK: Partner alcohol use, violence and women's mental health: population-based survey in India. $\mathrm{Br} J$ Psychiatry 2010, 196:192-199.

27. Hegarty K: Domestic violence: the hidden epidemic associated with mental illness. Br J Psychiatry 2011, 198:169-170.

28. Romito P, Molzan Turan J, De Marchi M: The impact of current and past interpersonal violence on women's mental health. Soc Sci Med 2005 60:1717-1727

29. Romito P, Grassi M: Does violence affect one gender more than the other? The mental health impact of violence among male and female university students. Soc Sci Med 2007, 65:1222-1234.

30. Ishida K, Stupp P, Melian M, Serbanescu F, Goodwin M: Exploring the associations between intimate partner violence and women's mental health: evidence from a population-based study in Paraguay. Soc Sci Med 2010, 71:1653-1661.

31. Fisher J, Tran T, Duc Tran T, Dwyer T, Nguyen T, Casey GJ, Anne Simpson J, Hanieh S, Biggs BA: Prevalence and risk factors for symptoms of common mental disorders in early and late pregnancy in Vietnamese women: a prospective population-based study. J Affect Dis 2013, 146:213-219.

32. Varma D, Chandra PS, Thomas T, Carey MP: Intimate partner violence and sexual coercion among pregnant women in India: Relationship with depression and post-traumatic stress disorder. J Affect Dis 2007, 102:227-235.

33. Melo EF Jr, Cecatti JG, Pacagnella RC, Leite DF, Vulcani DE, Makuch MY: The prevalence of perinatal depression and its associated factors in two different settings in Brazil. J Affect Dis 2012, 136:1204-1208.

34. Sawyer A, Ayers S, Smith H: Pre- and postnatal psychological wellbeing in Africa: a systematic review. J Affect Dis 2010, 123:17-29.

35. Leung WC, Kung F, Lam J, Leung TW, Ho PC: Domestic violence and postnatal depression in a Chinese community. Int J Gynaecol Obstet 2002, 79:159-166.

36. Romito P, Pomicino L, Lucchetta C, Scrimin F, Turan JM: The relationships between physical violence, verbal abuse and women's psychological distress during the postpartum period. J Psychosom Obstet Gynecol 2009, 30:115-121.

37. Cohen MM, Schei B, Ansara D, Gallop R, Stuckless N, Stewart DE: A history of personal violence and postpartum depression: is there a link? Arch Womens Ment Health 2002, 4:83-92.

38. Records K, Rice MJ: Lifetime physical and sexual abuse and the risk for depression symptoms in the first 8 months after birth. J Psychosom Obstet Gynecol 2009, 30:181-190.

39. Gomez-Beloz A, Williams MA, Sanchez SE, Lam N: Intimate partner violence and risk for depression among postpartum women in Lima, Peru. Violence Vict 2009, 24:380-398.

40. Ali NS, Ali BS, Azam IS: Post partum anxiety and depression in peri-urban communities of Karachi, Pakistan: a quasi-experimental study. BMC Public Health 2009, 12:384.

41. Ludermir AB, Schraiber LB, D'Oliveira AFPL, Ivan França-Junior I, Jansen HA: Violence against women by their intimate partner and common mental disorders. Soc Sci Med 2008, 66:1008-1018.

42. Tiwari A, Chan KL, Fong D, Leung WC, Brownridge DA, Lam H, Wong B, Lam CM, Chau F, Chan A, Cheung KB, Ho PC: The impact of psychological abuse by an intimate partner on the mental health of pregnant women. BJOG 2008, 115:377-384

43. Reichenheim ME, Moraes CL, Oliveira ASD, Lobato G: Revisiting the dimensional structure of the Edinburgh Postnatal Depression Scale (EPDS): empirical evidence for a general factor. BMC-Med Res Methodol 2011, 11:94.

44. Moraes $\mathrm{CL}$, de Oliveira AS, Reichenheim ME, Lobato G: Severe physical violence between intimate partners during pregnancy: a risk factor for early cessation of exclusive breast-feeding. Public Health Nutr 2011, 14:2148-2155.

45. Lobato $G$, Moraes $C L$, Dias AS, Reichenheim ME: Alcohol misuse among partners: a potential effect modifier in the relationship between physical intimate partner violence and postpartum depression. Soc Psychiatry Psychiatr Epidemiol 2012, 47:427-438.

46. Lobato G, Brunner MA, Dias MA, Moraes CL, Reichenheim ME: Higher rates of postpartum depression among women lacking care after childbirth: clinical and epidemiological importance of missed postnatal visits. Arch Womens Ment Health 2012, 15:145-146.

47. Lobato $G$, Moraes $C L$, Dias AS, Reichenheim ME: Postpartum depression according to time frames and sub-groups: a survey in primary health care settings in Rio de Janeiro, Brazil. Arch Womens Ment Health 2011, 14:187-193. 
48. Sampaio PF, Moraes CL, Reichenheim ME, Oliveira AS, Lobato G: [Birth in Baby-Friendly Hospitals in Rio de Janeiro, Brazil: a protective factor for breastfeeding?]. Cad Saude Publica 2011, 27:1349-1361.

49. Alexandre GC, Nadanovsky P, Moraes CL, Reichenheim M: The presence of a stepfather and child physical abuse, as reported by a sample of Brazilian mothers in Rio de Janeiro. Child Abuse Negl 2010, 34:959-966.

50. Alexandre GC, Nadanovsky P, Wilson M, Daly M, Moraes CL, Reichenheim M: Cues of paternal uncertainty and father to child physical abuse as reported by mothers in Rio de Janeiro, Brazil. Child Abuse Negl 2011 35:567-573.

51. Bottino MN, Nadanovsky P, Moraes CL, Reichenheim ME, Lobato G: Reappraising the relationship between maternal age and postpartum depression according to the evolutionary theory: Empirical evidence from a survey in primary health services. J Affect Dis 2012, 142:219-224.

52. Brazilian Criterion of Economic Classification. http://www.abep.org/new/ Servicos/Download.aspx?id=08.

53. Reichenheim ME, Harpham T: An intra-community profile of nutritional deficiency: a study of children under 5 years of age in a low-income community in Rio de Janeiro (Brazil). Rev Saude Publica 1990, 24:69-79.

54. Russell M, Martier SS, Sokol RJ, Mudar P, Bottoms S, Jacobson S, Jacobson J: Screening for pregnancy risk-drinking. Alcohol Clin Exp Res 1994, 18:1156-1161.

55. Moraes CL, Viellas EF, Reichenheim ME: Assessing alcohol misuse during pregnancy: evaluating psychometric properties of the CAGE, T-ACE, and TWEAK in a Brazilian setting. J Stud Alcohol 2005, 66:165-173.

56. Mayfield D, McLeod G, Hall P: The CAGE questionnaire: validation of a new alcoholism screening instrument. Am J Psych 1974, 131:1121-1123.

57. Ewing JA: Detecting alcoholism: The CAGE questionnaire. JAMA 1984, 252:1905-1907.

58. Masur J, Monteiro MG: Validation of the "CAGE" alcoholism screening test in a Brazilian psychiatric inpatient hospital setting. Braz J Med Biol Res 1983, 16:215-218.

59. Smart RG, Arif A, Hughes $P$, Medina Mora ME, Navaratnam V, Varma VK, Wadud KA: Drugs use among non-student youth. In. Geneva: World Health Organization; 1981

60. Straus MA, Hamby SL, Boney-McCoy S, Sugarman DB: The revised Conflict Tactics Scales (CTS2): Development and preliminary psychometric data. J Fam Issues 1996, 17:283-316.

61. Moraes CL, Hasselmann MH, Reichenheim ME: Portuguese-language cross-cultural adaptation of the Revised Conflict Tactics Scales (CTS2), an instrument used to identify violence in couples. Cad Saude Publica 2002, 18:163-176.

62. Moraes $\mathrm{CL}$, Reichenheim ME: Cross-cultural measurement equivalence of the Revised Conflict Tactics Scales (CTS2) Portuguese version used to identify violence within couples. Cad Saude Publica 2002, 18:783-796.

63. Harding TW, de Arango MV, Baltazar J, Climent CE, Ibrahim HH, Ladrido-Ignacio L, Murthy RS, Wig NN: Mental disorders in primary health care: a study of their frequency and diagnosis in four developing countries. Psychol Med 1980, 10:231-241.

64. Harpham T, Reichenheim ME, Oser R, Thomas E, Hamid N, Jaswal S, Ludermir A, Aidoo M: How to measure mental health in a cost-effective manner. Health Policy Plan 2003, 18:344-349.

65. Mari JJ, Williams P: Misclassification by psychiatric screening questionnaires. J Chron Dis 1986, 39:371-378.

66. Mari JJ, Williams $\mathrm{P}:$ A validity study of a psychiatric screening questionnaire (SRQ-20) in primary care in the city of Sao Paulo. Br J Psychiatry 1986, $148: 23-26$.

67. Goldberg DP, Blackwell B: Psychiatric illness in general practice. A detailed study using a new method of case identification. Br Med J 1970, 1:439-443.

68. Scazufca M, Menezes PR, Vallada H, Araya R: Validity of the self reporting questionnaire-20 in epidemiological studies with older adults: results from the Sao Paulo Ageing \& Health Study. Soc Psychiatry Psychiatr Epidemiol 2009, 44:247-254.

69. lacoponi E, Mari JJ: Reliability and factor structure of the Portuguese version of Self-Reporting Questionnaire. Int J Soc Psychiatry 1989, 35:213-222.

70. Santos KO, Araujo TM, Oliveira NF: [Factor structure and internal consistency of the Self-Reporting Questionnaire (SRQ-20) in an urban population]. Cadernos de Saúe Pública 2009, 25:214-222.

71. Muthén LK, Muthén BO: Mplus User's Guide. 7th edition. Los Angeles: Muthén \& Muthén; 1998-2012.

72. Kline RB: Principles and practice of structural equation modeling. 3rd edition. London: The Guilford Press; 2011.
73. Brown TA: Confirmatory Factor Analysis for Applied Research. New York: The Guilford Press; 2006.

74. Hu L, Bentler PM: Cutoff criteria for fit indexes in covariance structure analysis: Conventional criteria versus new alternatives. Struct Equ Modeling 1999, 6:1-55.

75. Hu L, Bentler PM: Fit indices in covariance structure modeling: Sensitivity to underparameterized model misspecification. Psychol Methods 1998, 3:424-453.

76. Browne MW, Cudeck R: Alternative ways of assessing model fit. In Testing structural equation models. Edited by Bollen KA, Long JS. London: Sage Publications Inc; 1993:136-162

77. Tucker $L R$, Lewis $C$ : A reliability coefficient for maximum likelihood factor analysis. Psychometrika 1973, 38:1-10

78. Schmidt Ml, Duncan BB, Azevedo e Silva G, Menezes AM, Monteiro CA, Barreto SM, Chor D, Menezes PR: Chronic non-communicable diseases in Brazil: burden and current challenges. Lancet 2011, 377:1949-1961.

79. Reichenheim ME, Souza ER, Moraes CL, Mello Jorge MH, Silva CM, Minayo MCS: Violence and injuries in Brazil: the effect, progress made, and challenges ahead. Lancet 2011, 377:1962-1975.

80. Woolhouse H, Gartland D, Hegarty K, Donath S, Brown SJ: Depressive symptoms and intimate partner violence in the 12 months after childbirth: a prospective pregnancy cohort study. BJOG 2012, 119:315-323.

81. Feld SL, Straus MA: Escalation and desistance of wife assault in marriage. Criminology 1989, 27:141-162

82. Beck CT: Predictors of postpartum depression: an update. Nurs Res 2001, 50:275-285.

83. O'Hara MW, Swain AM: Rates and risks of postpartum depression: a meta- analysis. Int Rev Psychiatry 1996, 8:37-54.

84. Xie RH, He G, Koszycki D, Walker M, Wen SW: Prenatal social support, postnatal social support, and postpartum depression. Ann Epidemiol 2009, 19:637-643.

85. Matt G, Vazquez C, Campbell WK: Mood-congruent recall of affectively toned stimuli: a meta-analytical review. Clin Psychol Rev 1992, 12:227-255.

86. Dennis CL, Creedy D: Psychosocial and psychological interventions for preventing postpartum depression. Cochrane Database Syst Rev 2013 28, CD001134.

87. Dennis $\mathrm{CL}$, Hodnett E: Psychosocial and psychological interventions for treating postpartum depression. Cochrane Database Syst Rev 2007, 17, CD006116.

88. Dennis $C L$, Ross $L E$, Herxheimer $A$ : Oestrogens and progestins for preventing and treating postpartum depression. Cochrane Database Syst Rev 2008, 8, CD001690.

89. Yawn BP, Dietrich AJ, Wollan P, Bertram S, Graham D, Huff J, Kurland M, Madison S, Pace WD: TRIPPD: a practice-based network effectiveness study of postpartum depression screening and management. Ann Fam Med 2012, 10:320-329.

90. Ho SM, Heh SS, Jevitt CM, Huang LH, Fu YY, Wang LL: Effectiveness of a discharge education program in reducing the severity of postpartum depression: a randomized controlled evaluation study. Patient Educ Couns 2009, 77:68-71.

91. Silverman ME, Loudon $\mathrm{H}$ : Antenatal reports of pre-pregnancy abuse is associated with symptoms of depression in the postpartum period. Arch Womens Ment Health 2010, 13:411-415.

92. Wilton G, Moberg DP, Fleming MF: The effect of brief alcohol intervention on postpartum depression. MCN Am J Matern Child Nurs 2009, 34:297-302.

doi:10.1186/1471-2458-14-427

Cite this article as: Reichenheim et al:: The role of intimate partner violence and other health-related social factors on postpartum common mental disorders: a survey-based structural equation modeling analysis. BMC Public Health 2014 14:427. 